\title{
CONTROLE DE FITONEMATOIDES POR BACILLUS SUBTILIS EM CANA-DE-AÇÚCAR
}

Rita de Cássia Lima Mazzuchelli ${ }^{1}$; Fabio Fernando de Araujo ${ }^{2}$.

1 Mestranda do Curso de Mestrado em Agronomia da UNOESTE; 2 Docente da UNOESTE. E-mail: ritamazzuchelli@yahoo.com.br

\section{RESUMO}

O objetivo do presente trabalho foi avaliar o controle de fitonematoides no solo, após a aplicação de nematicidas no momento do plantio e em cobertura na cultura da cana-de-açúcar. $O$ experimento foi realizado em uma usina de açúcar e álcool localizada no município de Caiabu - SP. O delineamento empregado foi de blocos casualizados com cinco repetições, com quatro tratamentos, dois genótipos, totalizando 40 parcelas. Os tratamentos conduzidos foram carbofurano, B. subtilis aplicado no momento do plantio, B. subtilis aplicado trinta dias após o plantio e controle. As coletas de solo foram realizadas aos 90, 180 e 270 dias após o plantio. Os dados obtidos foram analisados estatisticamente pelo programa SISVAR, sendo utilizado o teste Tukey a $1 \%$ para comparação das médias. O controle biológico com o uso de $B$. subtlis reduziu a comunidade de fitonematoides no solo de forma semelhante ao controle químico com carbofurano.

Palavras-chave: Saccharum, Meloidogyne, Pratylenchus, solo, rizobactéria.

\section{INTRODUÇÃO}

A cana-de-açúcar (Saccharum spp.) é uma das culturas mais importantes no cenário nacional, devido ser a matéria-prima utilizada pela indústria sucroalcooleira para a produção de seus dois principais produtos o açúcar e o álcool (BENETT et al., 2011).

A cana-de-açúcar vem sendo cultivada na maioria das vezes como um monocultivo, causando alguns problemas de pressão de pragas, entre eles os nematoides, que causam grande dano ao sistema radicular das plantas, tornando-os deficientes, diminuindo a produtividade agrícola (BARROS et al., 2010).

O ataque de nematoides à cana-de-açúcar é através de suas raízes, de onde extraem nutrientes para o crescimento e desenvolvimento. O prejuízo à parte aérea é reflexo de um sistema radicular debilitado, incapaz de absorver água e nutrientes necessários para o bom desenvolvimento das plantas, em condições de campo são verificados reboleiras de plantas menores e cloróticas (DINARDO-MIRANDA, 2005).

A aplicação de nematicidas diminui o número de nematoides, contribuindo assim para um melhor desenvolvimento das plantas, aumentando a sua produtividade na ordem de $15 \%$ para genótipos suscetíveis (DINARDO-MIRANDA et al., 1996), porém a utilização de nematicidas 
Encontro de Ensino, Pesquisa e Extensão, Presidente Prudente, 21 a 24 de outubro, 2013

químicos nem sempre têm sido satisfatórias, evidenciando assim necessidades de pesquisas na área (BARROS et al., 2000).

Araújo e Marchesi (2009) constataram que a aplicação de B. subtilis aumentou a biomassa da parte aérea e reduziu a reprodução de nematoides formadores de galhas em tomate. Estudos de Araújo et al. (2002) constataram que a presença de Bacillus subtilis afetou a orientação do nematoide Heterodera glycines reduzindo a sua migração em direção a raiz da soja.

O objetivo do presente trabalho foi avaliar o controle de fitonematoides no solo após a aplicação de nematicidas no momento do plantio e em cobertura na cultura da cana-de-açúcar.

\section{METODOLOGIA}

O experimento foi desenvolvido em parceria com a Usina Alto Alegre - Unidade Floresta Presidente Prudente, em uma área com histórico de infestação de nematoides, no município de Caiabu a uma latitude $22 \circ 00^{\prime} 44^{\prime \prime}$ sul e a uma longitude 51 1914'08" oeste, a uma altitude de 520 metros.

$\mathrm{A}$ análise de solo da área apresentou o seguinte perfil de fertilidade $\mathrm{pH}$ em $\mathrm{CaCl}_{2}=4,6$; M.O.= $9 \mathrm{~g} \mathrm{dm}^{-3} ; \mathrm{P}=10 \mathrm{mg} \mathrm{dm}^{-3} ; \mathrm{K}=0,6 \mathrm{mmolc} \mathrm{dm}^{-3} ; \mathrm{Ca}=11 \mathrm{mmolc} \mathrm{dm}^{-3} ; \mathrm{Mg}=6 \mathrm{mmolc} \mathrm{dm}^{-3}$; $\mathrm{H}+\mathrm{Al}=13 \mathrm{mmolc} \mathrm{dm}{ }^{-3} ; \mathrm{Al}=0 \mathrm{mmolc} \mathrm{dm}^{-3} ; \mathrm{SB}=18 \mathrm{mmolc} \mathrm{dm}^{-3} ; \mathrm{CTC}=31 \mathrm{mmolc} \mathrm{dm}^{-3} ; \mathrm{V} \%=58 \%$; $M \%=0 \%$.

Foram retiradas amostras de solo e encaminhadas ao laboratório de Microbiologia da Unoeste para identificação de espécies de fitonematoides e contagem populacional. Encontrou-se em média 280 nematoides em 100g de solo, sendo 180 do gênero Meloidogyne, 100 do gênero Pratylenchus.

Foram utilizadas no experimento dois genótipos de cana-de-açúcar susceptíveis a ação de nematoides, SP81-3250 e RB867515. O delineamento empregado foi de blocos casualizados, com quatro tratamentos, cinco repetições, sendo 20 parcelas para cada genótipo, totalizando 40 parcelas.

Os tratamentos conduzidos para controle de fitonematoides foram carbofurano, B. subtilis aplicado no momento do plantio, B. subtilis aplicado trinta dias após o plantio e controle. Cada parcela possuía 6 metros de largura, por 10 metros de comprimento com cinco sulcos espaçados a 1,5 m. A área total para cada genótipo possuía 62 metros de comprimento por 31,5 metros de largura.

A aplicação do controle biológico foi efetivada por duas formas: aplicação da rizobactéria no sulco de plantio, e aplicação trinta dias após o plantio. Como referência de controle de 
nematoides foi efetivado o tratamento químico com carbofurano no sulco de plantio. Foi conduzido um tratamento controle, sem aplicação de controle químico ou biológico.

Para efetivação do controle biológico, ocorreu a formação de uma suspensão de células bacterianas (100 mL), que foi dissolvida em 12,5 litros de água, aplicando-se 0,250 litros para 10 metros lineares de sulco. O tratamento químico com carbofurano foi realizado dissolvendo 0,6 litros do produto comercial, em 18 litros de água, aplicando-se 0,360 litros para 10 metros lineares de sulco.

Para o plantio da cana-de-açúcar, foram distribuídos nos sulcos os dois colmos, proporcionando uma distribuição de 17 a 20 gemas por metro linear de sulco. As mudas de cana depositadas no fundo do sulco foram cortadas em toletes, com 2 a 3 gemas, aplicados os tratamentos e após o recobrimento com máquina.

Foram retiradas amostras de solo aos 90, 180 e 270 dias após o plantio, para contagem e identificação de nematoides. Os nematoides do solo foram extraídos de alíquotas de $100 \mathrm{~cm}^{3}$ pela técnica de Jenkins (1964). Após será realizada a contagem com auxílio da câmara de Peters, no microscópio óptico, para análise de nematoides dos gêneros Meloidogyne e Pratylenchus.

Os resultados obtidos foram submetidos à análise de variância, através do programa computacional Sistema de Análise de Variâncias - SISVAR (FERREIRA, 2000), sendo as médias comparadas pelo teste Tukey.

\section{RESULTADOS}

A população de nematoides do gênero Meloidogyne aos 90 dias nos tratamentos com carbofurano e a rizobactéria aplicada no momento do plantio diferiram significativamente em relação ao tratamento com a rizobactéria aplicada após trinta dias do plantio e, do controle para o genótipo SP81-3250. Para o genótipo RB867515 todos os tratamentos realizados diferiram significativamente do controle, apresentando os menores valores populacionais (Tabela 1).

Os nematoides do gênero Pratylenchus apresentaram os menores valores populacionais na avaliação realizada aos 90 dias nos tratamentos com carbofurano, rizobactéria aplicada no sulco no momento do plantio, seguidos pela aplicação da rizobactéria aos trinta dias na pós-emergência, já o controle apresentou os maiores valores populacionais em ambos os genótipos utilizados no experimento (Tabela 1).

Na avaliação realizada aos 180 dias para o genótipo SP81-3250 a população de nematoides do gênero Meloidogyne diferiu em todos os tratamentos em relação ao controle. Mas para o genótipo RB867515 o tratamento com carbofurano, e a rizobactéria no sulco de plantio 
apresentaram os menores índices populacionais em relação aos demais tratamentos, a aplicação da rizobactéria trinta dias após o plantio possibilitou um controle em relação ao controle, porém com valores populacionais mais elevados comparados com os outros tratamentos. Os tratamentos com carbofurano, rizobactéria aplicada no momento do plantio e 30 dias após o plantio foram as mais eficientes no controle populacional de nematoides na avaliação no solo em ambos os genótipos utilizadas no experimento.

A avaliação realizada aos 270 dias após o plantio apresentou que as formas ativas de nematoides do gênero Meloidogyne foram menores para os tratamentos com carbofurano, rizobactérias aplicadas no sulco e em pós-emergência, diferindo do controle, para ambos os genótipos utilizados. As formas ativas de nematoides do gênero Pratylenchus, apresentaram menores valores para os tratamentos realizados, carbofurano, rizobactéria no sulco de plantio e rizobactéria após a emergência, diferindo assim do controle nos dois genótipos utilizados.

Tabela 1. Incidência de nematoides do gênero Meloidogyne e Pratylenchus no solo cultivado com cana-de-açúcar (genótipos SP81-3250 e RB867515) após tratamento com nematicidas no sulco e na pós-emergência. Avaliação efetuada aos 90, 180 e 270 dias após o plantio.

\begin{tabular}{|c|c|c|c|c|}
\hline & \multicolumn{4}{|c|}{ Formas ativas de nematoides em $100 \mathrm{~cm}^{3}$ de solo } \\
\hline & \multicolumn{2}{|c|}{ Meloidogyne spp. } & \multicolumn{2}{|c|}{ Pratylenchus spp. } \\
\hline & SP81-3250 & RB867515 & SP81-3250 & RB867515 \\
\hline Tratamentos & \multicolumn{4}{|c|}{90 dias } \\
\hline Carbofurano & $112,0 \pm 29,9 b$ & $128,0 \pm 29,9 b$ & $240,0 \pm 21,6 c$ & $240,0 \pm 21,6 c$ \\
\hline B. s. (sulco) & $144,0 \pm 29,9 b$ & $144,0 \pm 29,9 b$ & $272,0 \pm 21,6 c$ & $224,0 \pm 21,6 c$ \\
\hline B. s. (pós) & $224,0 \pm 29,9 a$ & $160,0 \pm 29,9 b$ & $400,0 \pm 21,6 b$ & $336,0 \pm 21,6 b$ \\
\hline Controle & $288,0 \pm 29,9 a$ & $272,0 \pm 29,9 a$ & $576,0 \pm 21,6 a$ & $544,0 \pm 21,6 a$ \\
\hline \multirow[t]{2}{*}{ Teste F } & $9,05^{* *}$ & $7,41^{* *}$ & $8,97^{* *}$ & $10,31^{* *}$ \\
\hline & \multicolumn{4}{|c|}{180 dias } \\
\hline Carbofurano & $176,0 \pm 25,7 b$ & $112,0 \pm 25,7 c$ & $160,0 \pm 20,4 b$ & $128,0 \pm 20,4 b$ \\
\hline B. s. (sulco) & $128,0 \pm 25,7 b$ & $64,0 \pm 25,7 c$ & $112,0 \pm 20,4 b$ & $80,0 \pm 20,4 b$ \\
\hline B. s. (pós) & $128,0 \pm 25,7 b$ & $176,0 \pm 25,7 b$ & $112,0 \pm 20,4 b$ & $160,0 \pm 20,4 b$ \\
\hline Controle & $256,0 \pm 25,7 a$ & $272,0 \pm 25,7 a$ & $256,0 \pm 20,4 \mathrm{a}$ & $272,0 \pm 20,4 a$ \\
\hline \multirow[t]{2}{*}{ Teste $\mathrm{F}$} & $8,76^{* *}$ & $11,23 * *$ & $10,20 * *$ & $9,34 * *$ \\
\hline & \multicolumn{4}{|c|}{270 dias } \\
\hline Carbofurano & $176,0 \pm 23,8 b$ & $192,0 \pm 23,8 b$ & $112,0 \pm 25,6 b$ & $160,0 \pm 25,6 b$ \\
\hline B. s. (sulco) & $112,0 \pm 23,8 b$ & $160,0 \pm 23,8 b$ & $112,0 \pm 25,6 b$ & $144,0 \pm 25,6 b$ \\
\hline B. s. (pós) & $144,0 \pm 23,8 b$ & $224,0 \pm 23,8 b$ & $160,0 \pm 25,6 b$ & $112,0 \pm 25,6 b$ \\
\hline Controle & $448,0 \pm 23,8 a$ & $464,0 \pm 23,8 a$ & $320,0 \pm 25,6 a$ & $336,0 \pm 25,6 a$ \\
\hline Teste F & $8,76^{* *}$ & $7,98 * *$ & $9,76^{* *}$ & $10,38 * *$ \\
\hline
\end{tabular}

B. s. (sulco) = Bacillus subtilis aplicado no sulco de plantio; B. s. (pós) = Bacillus subtilis aplicado em pós-emergência; 1 . Médias seguidas de mesma letra não diferem estatisticamente pelo teste Tukey (1\%) EPM= erro padrão da média. 


\section{DISCUSSÃO}

A produção de substâncias tóxicas ou repelentes realizadas por rizobactérias podem desestimular a penetração ou alimentação de nematoides (FREITAS, 2001). Conforme o constatado por Silveira (2001) as rizobactérias podem atuar na infectividade, virulência e agressividade do patógeno, e também nos processos de infecção, desenvolvimento de sintomas e reprodução. Este fato foi evidenciado por Araújo et al. (2002) que constatou que a utilização de Bacillus subtilis afeta a orientação do nematoide, reduzindo a migração para a raiz, já que o $B$. subtilis interfere na produção de exsudados das raízes que servem como orientação para nematoides, alterando assim a reprodução e orientação do parasita em direção as raízes.

Araújo, Silva e Araújo (2002) constataram que a presença de Bacillus subtilis afetou a orientação do nematoide Heterodera glycines, reduzindo a sua migração em direção a raiz de soja.

Higaki e Araujo (2012) observaram efeitos no controle de nematoides em algodoeiro proporcionado por Bacillus subtilis, que reduziu estes patógenos de forma semelhante ao controle químico. O controle de nematoides e o aumento no crescimento das plantas, em função dos tratamentos efetuados, foram mais significativos no solo com maior infestação dos patógenos.

Estudos de Cardozo e Araujo (2011) com a aplicação de Bacillus subtilis em suspensão aquosa evidenciaram que esta bactéria promoveu o crescimento e a redução da reprodução dos nematoides em cana-de-açúcar durante a condução do experimento. A inoculação de bactérias nos canaviais pode contribuir de forma positiva, resultando em ganhos de produtividade, sendo que sua contribuição é diferente entre genótipos e entre as estirpes inoculadas, havendo assim uma interação entre estes fatores (PEREIRA et al., 2013).

O controle de nematoides em áreas de cultivo de cana-de-açúcar é realizado principalmente, com nematicidas químicos. Em estudos com a utilização de nematicida carbofurano Dinardo-Miranda et al. (1996) concluíram que sua aplicação resultou em evidente redução das populações de nematoides nas raízes, resultando em incrementos significativos na produção.

É necessária a utilização de medidas que sejam menos agressivas ao homem e ao ambiente, mas de maneira eficaz. A utilização de nematicidas são economicamente inviáveis, e pouco eficientes para a aplicação no solo em grandes áreas (GOULART, 2008). A utilização de Bacillus subtilis no controle populacional de nematoides é promissora, porém os gastos referentes à sua utilização ainda não podem ser mensuráveis, devido ao controle realizado ser de forma experimental. 
Encontro de Ensino, Pesquisa e Extensão, Presidente Prudente, 21 a 24 de outubro, 2013

A aplicação de Bacillus subtilis no controle de nematoides em cana-de-açúcar pode ser considerada um método alternativo para ser aplicado no manejo integrado de nematoides. Esta opção pode também ser interessante para os sistemas de produção da cana-de-açúcar orgânica. Foi comprovado neste trabalho que a eficiência do controle biológico de nematoides foi semelhante ao uso dos nematicidas convencionais.

\section{CONCLUSÃO}

O controle biológico com o uso de Bacillus subtilis, reduziu a comunidade fitonematoides no solo, de forma semelhante ao controle químico com carbofurano.

\section{REFERÊNCIAS}

ARAÚJO, F. F.; MARCHESI, G. V. P. Uso de Bacillus subtilis no controle da meloidoginose e na promoção do crescimento do tomateiro. Ciência Rural, vol.39, n.5, p. 1558-1561. 2009. http://dx.doi.org/10.1590/S0103-84782009000500039

ARAÚJO, F.F; SILVA, J.F.V.; ARAÚJO, A.S.F. Influência de Bacillus subtilis na eclosão, orientação e infecção de Heterodera glycines em soja. Ciência Rural, v.32, n.2, p.197-203, 2002.

http://dx.doi.org/10.1590/S0103-84782002000200003

BARROS, P.A.; CARDOSO, M.E.; LEITÃO, D.A.S.H.; PEDROSA, E.M.R.; MONTENEGRO, A.A.A.; MIRANDA, T.L. Distribuição espacial de nematoides e matéria orgânica em solo cultivado com cana-de-açúcar. X Jornada de Ensino, Pesquisa e Extensão — UFRPE: Recife. Jepex. 2010.

BARROS, A.C.B.; MOURA, R.M.; PEDROSA, E.M.R. Aplicação de Terbufos no controle de Meloidogyne incognita Raça 1 e Pratylenchus zeae em cinco variedades de cana-de-açúcar no nordeste efeitos na cana planta. Nematologia Brasileira, v. 24(1) p. 73-78. 2000.

BENETT, C.G.S., BUZETTI, S.; SILVA, K.S.; TEIXEIRA FILHO, M.C.M.; DE PAULA GARCIA, C.M.; MAESTRELO, P.R. Produtividade e desenvolvimento da cana-planta e soca em função de doses e fontes de manganês. Revista Brasileira de Ciência do Solo, v. 35, n. 5, p. 1661-1668, 2011.

CARDOZO, R. B.; ARAUJO, F. F. Multiplicação de Bacillus subtilis em vinhaça e viabilidade no controle da meloidoginose, em cana-de-açúcar. Revista brasileira engenharia agrícola e ambiental, Campina Grande, v.15, n.12, p. 1283-1288, 2011.

DINARDO-MIRANDA, L. L. Nematoides e pragas de solo em cana-de-açúcar. Encarte do informações agronômicas № 110. Potafos. 2005. p.25-32.

DINARDO-MIRANDA, L. L.; MORELLI, J. L.; LANDELL, M. G. A.; SILVA, M. A. Comportamento de genótipos de cana-de-açúcar em relação a Pratylenchus zeae. Nematologia Brasileira, v. 20, n. 2, p. 52-58. 1996. 
FERREIRA, D. F. Análise estatística por meio do SISVAR (Sistema para Análise de Variância) para Windows versão 4.0. In: Reunião anual da Região Brasileira Da Sociedade Internacional de Biometria, 45., 2000, São Carlos. Anais... São Carlos: UFSCar, p. 255-258. 2000.

FREITAS, L.G. Rizobactérias versus nematoides. 2001. Online Disponível em: http://www.ufv.br/dpf/labnematologia/rizo.pdf. Acesso em: fev. 2013.

GOULART, A. M. C. Aspectos gerais sobre nematoides das lesões radiculares (gênero Pratylenchus). Embrapa, Planaltina, Documentos 219. 27p. 2008.

HIGAKI, W. A.; ARAUJO, F. F. Bacillus subtilis e abamectina no controle de nematoides e alterações fisiológicas em algodoeiro cultivado em solos naturalmente infestados. Nematropica, 42(2), 295303. 2012.

JENKINS, W. R. A rapid centrifugal - flotation technique for separating nematodes from soil. Plant Diasease Report, v. 48, 1964. p. 692.

PEREIRA, W.; LEITE, J. M.; HIPÓLITO, G. S.; SANTOS, C. L. R.; REIS, V. M. Acúmulo de biomassa em genótipos de cana-de-açúcar inoculadas com diferentes estirpes de bactérias diazotróficas.

Revista Ciência Agronômica, Fortaleza, v. 44, n. 2, p. 363-370, 2013.

http://dx.doi.org/10.1590/S1806-66902013000200020

SILVEIRA, E.B. Bactérias promotoras de crescimento de plantas e biocontrole de doenças. In: MICHEREFF, S.J.; BARROS, R. Proteção de plantas na agricultura sustentável.Recife : UFRPE, Imprensa Universitária. 2001. p. 70- 100. 